\title{
Pedagogo hospitalar: os desafios e a atuação em prol dos pacientes através da prática
}

\section{pedagógica}

\author{
Hospital educational education: the challenges and action to provide patients through pedagogical \\ practice
}

Educación educativa hospitalaria: los desafíos y la acción para proporcionar a los pacientes a

través de la práctica pedagógica

Recebido: 10/11/2021 | Revisado: 15/11/2021 | Aceito: 15/11/2021 | Publicado: 17/11/2021

\author{
Samara da Silva Balbino \\ ORCID: https://orcid.org/0000-0002-4736-3314 \\ Instituto Educacional Santa Catarina - Faculdade Guaraí, Brasil \\ E-mail: samara.silva.balbino19@gmail.com \\ Millena Gonçalves Rodrigues \\ ORCID: https://orcid.org/0000-0001-5312-753X \\ Instituto Educacional Santa Catarina - Faculdade Guaraí, Brasil \\ E-mail: rodriguesmillena5@gmail.com \\ Adriana Keila Dias \\ ORCID: https://orcid.org/0000-0003-1291-5593 \\ Instituto Educacional Santa Catarina - Faculdade Guaraí, Brasil \\ E-mail: adrianakeiladias@hotmail.com
}

\begin{abstract}
Resumo
A importância da pedagogia hospitalar no atendimento de crianças e adolescentes hospitalizados, que devem ter o direito e acesso do ensino aprendizagem de forma lúdica para que não percam ao ano letivo. $\mathrm{O}$ trabalho do pedagogo neste ambiente deve estar vinculado com as praticas pedagógicas, pois é um processo que tende a ter necessidade de atenção e reflexão para que a educação seja mais flexível para as crianças e adolescentes que ali se encontra. Considerando as informações, objetivo do presente estudo é abordar os desafios do pedagogo no ambiente hospitalar e compreender os processos da pedagogia hospitalar no contexto das crianças/pacientes e a atuação dos pedagogos. Este documento foi construído através de buscas realizadas em plataformas de pesquisas como, o Google Acadêmico, repositórios de faculdades, entre outras paginas da internet. De forma geral, foi possível perceber que o trabalho realizado pelo pedagogo hospitalar é de suma importância, pois através deste trabalho crianças e adolescentes hospitalizados receberam de forma correta e lúdica os processos do ensino-aprendizagem onde apresentaram por meio deste trabalho um certo grau de desenvolvimento cognitivo, tendo a continuação dos seus estudos dentro do hospital com entusiasmo e uma boa autoestima.
\end{abstract}

Palavras-chave: Escolarização; Atividade; Classe Hospitalar.

\begin{abstract}
The importance of hospital pedagogy in the care of hospitalized children and adolescents, who must have the right and access to teaching and learning in a playful way so that they do not miss the school year. The work of the pedagogue in this environment must be linked to pedagogical practices, as it is a process that tends to need attention and reflection so that education is more flexible for the children and adolescents who are there. Considering the information, the objective of this study is to address the challenges of the pedagogue in the hospital environment and to understand the processes of hospital pedagogy in the context of children/patients and the role of pedagogues. This document was built through searches carried out on research platforms such as Google Scholar, college repositories, among other websites. In general, it was possible to see that the work carried out by the hospital pedagogue is of paramount importance, because through this work hospitalized children and adolescents received in a correct and playful way the teaching-learning processes where they presented, through this work, a certain degree of development cognitive, having continued their studies within the hospital with enthusiasm and good self-esteem.
\end{abstract}

Keywords: Schooling; Activity; Hospital Class.

\section{Resumen}

La importancia de la pedagogía hospitalaria en la atención de los niños y adolescentes hospitalizados, quienes deben tener el derecho y el acceso a la enseñanza y el aprendizaje de manera lúdica para que no se pierdan el año escolar. El trabajo del pedagogo en este entorno debe estar vinculado a las prácticas pedagógicas, ya que es un proceso que suele necesitar atención y reflexión para que la educación sea más flexible para los niños, niñas y adolescentes que allí se 
encuentran. Considerando la información, el objetivo de este estudio es abordar los desafíos del pedagogo en el ámbito hospitalario y comprender los procesos de la pedagogía hospitalaria en el contexto de niños / pacientes y el rol de los pedagogos. Este documento se construyó a través de búsquedas realizadas en plataformas de investigación como Google Scholar, repositorios universitarios, entre otros sitios web. En general, se pudo constatar que el trabajo que realiza el pedagogo hospitalario es de suma importancia, pues a través de este trabajo los niños y adolescentes hospitalizados recibieron de manera correcta y lúdica los procesos de enseñanza-aprendizaje donde presentaron, a través de este trabajo, cierto grado de desarrollo cognitivo, habiendo continuado sus estudios dentro del hospital con entusiasmo y buena autoestima.

Palabras clave: Enseñanza; Actividad; Clase de Hospital.

\section{Introdução}

É de conhecimento que atuação o pedagogo abrange várias áreas, porém, quando se refere ao curso de pedagogia logo é associado para uma escola ou sala de aula cheia de criança, no entanto o pedagogo pode atuar tanto no âmbito escolar como ambiente hospitalar. Sendo assim, a Pedagogia Hospitalar é um processo alternativo da educação continuada que ultrapassa o contexto formal da escola, pois levanta parâmetros para atendimento de necessidades especiais transitórias do educando, em ambiente hospitalar e/ou domiciliar. Trata-se de uma nova realidade multi/Inter/transdisciplinar com características educativas. (Matos \& Mugiatti,2017).

Nesse contexto é importante ressaltar os direitos do estado e da família, de acordo com a constituição federal de 1988, no Art. 205, onde deve ser promovida e incentivada com a colaboração da sociedade.

A pedagogia hospitalar visa atender as necessidades das crianças e adolescentes que por motivo de doença se encontram hospitalizadas, sem poder manter contato com a escola, essa nova prática de educação tem como objetivo principal ajudar para que essas crianças e adolescentes hospitalizadas não percam ao ano letivo. De acordo com o Estatuto da Criança e do Adolescente hospitalizado, na resolução n ${ }^{\circ}$ 41, 13 de outubro de 1995, no inciso 9, afirma o "Direito de desfrutar de alguma forma de recreação, programas de educação para saúde, acompanhamento do currículo escolar durante sua permanência hospitalar.” (BRASIL,1996).

De acordo com as Diretrizes Nacionais para a Educação Especial na Educação Básica, que, na resolução n02/01CNE/CEB sobre a educação especial nos traz que:

A educação especial entende-se como um processo definido por uma proposta pedagógica que assegure recursos e serviços educacionais especiais, organizados institucionalmente para apoiar, complementar, suplementar e em alguns casos, substituir os serviços educacionais comuns, de modo a garantira educação escolares e promover o desenvolvimento das potencialidades dos educandos que apresentam necessidades educacionais especiais, em todas as etapas e modalidades da educação básica.

Sendo assim, o pedagogo juntamente com hospital precisa buscar meios e métodos qualificados, e criar um planejamento que seja estruturado e flexível cabendo atender as necessidades de cada paciente/aluno, pois a educação é para todos e se torna fundamental independentemente da situação e condições que se encontra a pessoa, a pedagogia hospitalar contribui para que as crianças e os adolescentes prossigam aprendendo. O trabalho do pedagogo neste ambiente deve estar vinculado com as práticas pedagógicas, pois é um processo que tende a ter necessidade de atenção e reflexão para que a educação seja mais flexível para as crianças e os adolescentes que ali se encontra, as atividades pedagógicas desenvolvidas para as crianças/adolescentes hospitalizados pode dar benefícios para que eles produzirem e reproduzirem a sensação que surge acerca do hospital, das rotinas, dos tratamentos e conceitos estabelecidos, pois essas atividades que são propostas agregam muito além do conhecimento, e sim este conteúdo trabalha a compreensão das crianças e adolescentes de forma lúdica e descontraída. 
Dentro desse novo espaço onde o pedagogo, não ira atuar de forma individual, mas sim em conjunto com a equipe do hospital que envolve todos os médicos, enfermeiros, pediatras e psicólogos, junto com essa equipe o pedagogo ira formular planejamentos, e atividades lúdicas para melhor atender as crianças e adolescentes hospitalizadas.

A Pedagogia Hospitalar também busca disponibilizar assessoria e atendimento emocional e humanístico tanto para paciente como para a família que muitas vezes esses pacientes não aceita de estarem em um espaço hospitalar pois pelo fato de esta longe de tudo acaba desenvolvendo transtornos emocionais como a raiva, insegurança e frustações que prejudicar a recuperação e é onde acaba sendo o desafio para o pedagogo, mesmo dentro do hospital tendo várias modalidades, como a Hospitalização Escolarizada, Classe Hospitalar, a Pedagogia Domiciliar e o Atendimento a criança em albergue ou casa de apoio, não se torna algo fácil para o pedagogo.

Com isso, o objetivo desse estudo é apresentar uma revisão bibliográfica a fim de construir um único documento abordando a importância do pedagogo dentro do ambiente hospitalar no processo de ensino-aprendizagem das crianças/adolescentes hospitalizados.

\section{Metodologia}

A pesquisa trata-se de uma metodologia descritiva exploratório com caráter qualitativo, e com revisão integrativa da literatura, tendo como método a pesquisa bibliográfica por meio de artigos científicos, pesquisas online.

A pesquisa bibliografia é desenvolvida com base em material já elaborado, constituído principalmente de artigos científicos. Embora em quase todos os estudos seja exibido algum tipo de trabalho dessa natureza, há pesquisas desenvolvidas exclusivamente a partir de fontes bibliográficas. Boa parte dos estudos exploratórios pode ser definida como pesquisas bibliográficas (Gil, 2002).

Para construção desse artigo, ocorreram informações através de diversos trabalhos científicos entre os anos 2011 a 2020, deste modo abordando o pedagogo hospitalar, aluno/paciente e a educação. Nesse sentido, esta pesquisa bibliográfica, encontra-se fundamentada teoricamente a partir das contribuições de pesquisadores renomados na área da Educação Especial, que abordam o tema Pedagogia Hospitalar.

Os artigos utilizados pelas estratégias de busca foram avaliados de forma totalmente dependente, pelo pesquisador, obedecendo aos critérios de inclusão: tempo de busca, sendo o alvo os pedagogos hospitalares, suas formas de trabalho e metodologias, e idioma português, o uso de uni termos, como; aluno/paciente, pedagogo hospitalar, desafios e atuação.

Figura 1: Fluxograma evidenciando o processo de seleção que foram incluídos no artigo.

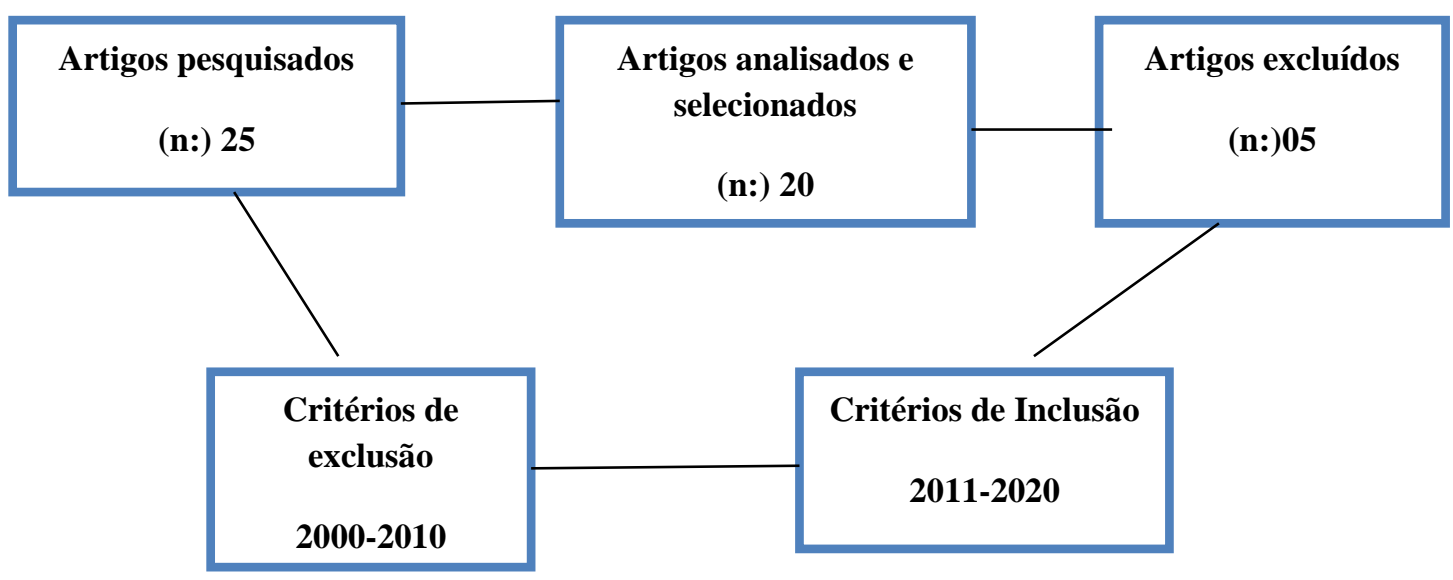

Fonte: Pesquisa dos autores (2021). 
Research, Society and Development, v. 10, n. 15, e230101523209, 2021

(CC BY 4.0) | ISSN 2525-3409 | DOI: http://dx.doi.org/10.33448/rsd-v10i15.23209

Quadro 1: Metodologia descritiva dos artigos utilizados nas referências bibliográficas

\begin{tabular}{|c|c|c|c|c|}
\hline Ano & País & Titulo & Objetivo & Revisão de Literatura \\
\hline 2017 & Petrópolis-RJ/ Brasil & $\begin{array}{ll}\text { A } & \text { humanização } \\
\text { integrando educação e } \\
\text { saúde. }\end{array}$ & $\begin{array}{l}\text { Levar conhecimento àqueles que } \\
\text { se encontram impossibilitados de } \\
\text { ir buscá-los é o caminho } \\
\text { apresentado pela obra. }\end{array}$ & $\begin{array}{l}\text { A pedagogia hospitalar é um } \\
\text { processo alternativo de educação } \\
\text { continuada que ultrapassa o } \\
\text { contexto formal da escola, pois } \\
\text { levanta parâmetros para o } \\
\text { atendimento de necessidades } \\
\text { especiais transitórias do educando, } \\
\text { em ambiente hospitalar e/ou } \\
\text { domiciliar. }\end{array}$ \\
\hline 2020 & Brasil & $\begin{array}{l}\text { Classe Hospitalar e o } \\
\text { direito a educação da } \\
\text { criança hospitalizada. }\end{array}$ & $\begin{array}{l}\text { Realizar uma reflexão sobre o } \\
\text { direito a educação da criança em } \\
\text { condição de enfermidade e de } \\
\text { hospitalização, tomando como } \\
\text { cenário a realidade do processo } \\
\text { educacional desenvolvido na } \\
\text { classe hospitalar de um hospital } \\
\text { público situado na região } \\
\text { metropolitana da Grande Vitória, } \\
\text { no estado do Espirito Santo, na } \\
\text { correlação com a legislação que } \\
\text { apregoa a manutenção de } \\
\text { educação para crianças e } \\
\text { adolescentes hospitalizados. }\end{array}$ & $\begin{array}{l}\text { No âmbito da classe hospitalar } \\
\text { pesquisada toda criança ou } \\
\text { adolescente que frequenta o } \\
\text { hospital, seja para realização de } \\
\text { acompanhamento ambulatorial, seja } \\
\text { em razão de internação, } \\
\text { independente do agravo, é } \\
\text { reconhecida como sujeito de } \\
\text { direito ao atendimento pedagógico } \\
\text { educacional ofertado à partir da } \\
\text { classe hospitalar. }\end{array}$ \\
\hline 2017 & $\begin{array}{l}\text { João Pessoa- PB/ } \\
\text { Brasil }\end{array}$ & $\begin{array}{l}\text { A importância da } \\
\text { pedagogia no ambiente } \\
\text { hospitalar. }\end{array}$ & $\begin{array}{l}\text { O objetivo central compreender o } \\
\text { papel que a Pedagogia exerce } \\
\text { nesse ambiente e o quanto as } \\
\text { ações pedagógicas são } \\
\text { importantes para a criança e } \\
\text { adolescente no decorrer da sua } \\
\text { hospitalização. }\end{array}$ & $\begin{array}{l}\text { A educação é a principal forma de } \\
\text { desenvolvimento de uma sociedade, } \\
\text { é através dela que nos } \\
\text { desenvolvemos, compreendemos e } \\
\text { crescemos como indivíduos ativos } \\
\text { no meio social. }\end{array}$ \\
\hline 2011 & Brasília-DF/ Brasil & $\begin{array}{l}\text { Desafios e possibilidades } \\
\text { da ludicidade no } \\
\text { atendimento pedagógico } \\
\text { hospitalar. }\end{array}$ & $\begin{array}{l}\text { Este trabalho tem como mote de } \\
\text { discussão central o lúdico como } \\
\text { recurso pedagógico nas classes } \\
\text { hospitalares. }\end{array}$ & $\begin{array}{l}\text { Definir e compreender } \\
\text { epistemologicamente a educação } \\
\text { lúdica e sua importância na prática } \\
\text { pedagógica trata-se de um "aprender } \\
\text { a conhecer" que combina desafio e } \\
\text { encanto. }\end{array}$ \\
\hline 2019 & Palmas- TO /Brasil & $\begin{array}{l}\text { As vozes das Professoras } \\
\text { na Pedagogia hospitalar: } \\
\text { descortinando } \\
\text { Possibilidades } \\
\text { enfrentamentos }\end{array}$ & $\begin{array}{l}\text { Busca conhecer o processo } \\
\text { pedagógico educacional em um } \\
\text { ambiente hospitalar, na atuação } \\
\text { das professoras, considerando as } \\
\text { especificidades de crianças em } \\
\text { tratamento de saúde, na cidade de } \\
\text { Palmas, estado do Tocantins, } \\
\text { Brasil. }\end{array}$ & $\begin{array}{l}\text { Entender a educação hospitalar } \\
\text { envolve questionamentos sobre as } \\
\text { possibilidades de o educando que } \\
\text { vivencia a situação de enfermidade } \\
\text { continuar o processo educacional } \\
\text { em consonância com a faixa etária e } \\
\text { fase escolar, mesmo em situação de } \\
\text { internação. Esse movimento passa }\end{array}$ \\
\hline
\end{tabular}


Research, Society and Development, v. 10, n. 15, e230101523209, 2021

(CC BY 4.0) | ISSN 2525-3409 | DOI: http://dx.doi.org/10.33448/rsd-v10i15.23209

\begin{tabular}{|c|c|c|c|c|}
\hline & & & & $\begin{array}{l}\text { pelo reconhecimento de que a } \\
\text { criança é sujeito de direitos e, } \\
\text { mesmo hospitalizada, mantém a } \\
\text { necessidade de vivenciar } \\
\text { experiências comuns à sua idade, } \\
\text { como o brincar e o estudar. }\end{array}$ \\
\hline 2012 & Campina Grande & $\begin{array}{l}\text { O lúdico no } \text { ambiente } \\
\text { hospitalar: } \\
\text { reflexões. }\end{array}$ & $\begin{array}{l}\text { Discutir a construção de saberes } \\
\text { docentes no contexto hospitalar } \\
\text { contribuindo para } \\
\text { desenvolvimento intelectual, } \\
\text { cultural e emocional e a } \\
\text { recuperação de crianças em } \\
\text { processo de internação. }\end{array}$ & $\begin{array}{l}\text { Nesse sentido, o brincar tem um } \\
\text { papel de grande relevância para o } \\
\text { desenvolvimento infantil, vez que } \\
\text { auxilia na construção do } \\
\text { conhecimento e quando } \\
\text { desenvolvido no ambiente } \\
\text { hospitalar contribui para trazer de } \\
\text { volta a autoestima da criança } \\
\text { enferma e, consequentemente, ajuda } \\
\text { na sua recuperação, já que } \\
\text { brincando, ela se expressa } \\
\text { naturalmente expondo suas ideias, } \\
\text { pensamentos, sentimentos, alegrias, } \\
\text { tristezas, conflitos que tem com o } \\
\text { mundo exterior, bem como com o } \\
\text { seu mundo interior. }\end{array}$ \\
\hline 2020 & Maranhão & $\begin{array}{l}\text { O pedagogo hospitalar: } \\
\text { atuação e contribuições. }\end{array}$ & $\begin{array}{l}\text { O objetivo do trabalho foi } \\
\text { conhecer mais detalhadamente o } \\
\text { que é a pedagogia hospitalar e } \\
\text { saber como o pedagogo atua no } \\
\text { hospital. }\end{array}$ & $\begin{array}{l}\text { O Pedagogo, em ambiente } \\
\text { hospitalar, trabalha dentro destas } \\
\text { três divisões da pedagogia } \\
\text { hospitalar, procurando de todas as } \\
\text { formas encontrar meios de envolver } \\
\text { a criança hospitalizada, a fim de } \\
\text { ajudar durante o período de } \\
\text { internação hospitalar, para que não } \\
\text { haja um total rompimento com a } \\
\text { escola na qual a criança } \\
\text { hospitalizada estava inserida. }\end{array}$ \\
\hline 2015 & Brasília & $\begin{array}{l}\text { A dimensão pedagógica } \\
\text { do pedagogo hospitalar. }\end{array}$ & $\begin{array}{l}\text { Objetivo geral analisar o papel } \\
\text { social do Pedagogo hospitalar e o } \\
\text { trabalho didático-pedagógico no } \\
\text { âmbito dos processos de ensino e } \\
\text { aprendizagem. }\end{array}$ & $\begin{array}{l}\text { Percebemos nesta descrição que o } \\
\text { papel social do pedagogo hospitalar } \\
\text { alcança o desenvolvimento da } \\
\text { cidadania do aluno-paciente, ou } \\
\text { seja, não se limita apenas a } \\
\text { transferência de conteúdos. }\end{array}$ \\
\hline 2018 & Campina Grande & $\begin{array}{l}\text { O papel do pedagogo na } \\
\text { classe hospitalar }\end{array}$ & $\begin{array}{l}\text { Objetivo de analisar como se dá a } \\
\text { relação pedagógica } \\
\text { administrativa do profissional de } \\
\text { pedagogia na Classe Hospitalar. }\end{array}$ & $\begin{array}{l}\text { O período de hospitalização, para } \\
\text { qualquer pessoa, é um momento de } \\
\text { dor, mas também de ressignificação. }\end{array}$ \\
\hline 2009 & Paraná & $\begin{array}{l}\text { O pedagogo frente aos } \\
\text { desafios da educação } \\
\text { hospitalar. }\end{array}$ & $\begin{array}{l}\text { O objetivo é sensibilizar o leitor } \\
\text { sobre a realidade hospitalar, a } \\
\text { situação do aluno enfermo, bem }\end{array}$ & $\begin{array}{l}\text { Atualmente, com a existência da } \\
\text { educação em ambiente hospitalar, a } \\
\text { relação professor aluno e a garantia }\end{array}$ \\
\hline
\end{tabular}


Research, Society and Development, v. 10, n. 15, e230101523209, 2021

(CC BY 4.0) | ISSN 2525-3409 | DOI: http://dx.doi.org/10.33448/rsd-v10i15.23209

\begin{tabular}{|c|c|c|c|c|}
\hline & & & $\begin{array}{l}\text { como destacar a participação } \\
\text { política/pedagógica do pedagogo } \\
\text { no processo de escolarização e a } \\
\text { importância de sua presença nas } \\
\text { políticas de humanização } \\
\text { hospitalares. }\end{array}$ & $\begin{array}{l}\text { do processo de ensino aprendizagem } \\
\text { é um processo que deve ser objeto } \\
\text { de atenção e reflexão para uma } \\
\text { educação mais flexível e responsiva } \\
\text { para as necessidades da criança e } \\
\text { adolescente, para que a alienação } \\
\text { seja superada e a prática pedagógica } \\
\text { no hospital seja verdadeiramente } \\
\text { libertadora e qualificada. }\end{array}$ \\
\hline 2016 & Brasil & $\begin{array}{l}\text { PEDAGOGIA } \\
\text { HOSPITALAR: METAS } \\
\text { E DESAFIOS PARA O } \\
\text { PEDAGOGO: Análise } \\
\text { dos principais desafios } \\
\text { enfrentados pelos } \\
\text { pedagogos que atuam em } \\
\text { hospitais e as metas que } \\
\text { almejam alcançar. }\end{array}$ & $\begin{array}{l}\text { O objetivo geral é compreender o } \\
\text { papel do pedagogo em ambiente } \\
\text { não escolar e sua importância ao } \\
\text { atuar na Pedagogia Hospitalar. }\end{array}$ & $\begin{array}{l}\text { A Pedagogia Hospitalar vem como } \\
\text { uma forma de minimizar os efeitos } \\
\text { negativos do quadro clínico e } \\
\text { psicológico do paciente, uma vez } \\
\text { que, ajuda na sua estabilidade } \\
\text { emocional, na continuidade de seus } \\
\text { estudos para que ele não fique } \\
\text { defasado. }\end{array}$ \\
\hline 2017 & Juína/MT/Brasil & $\begin{array}{l}\text { PEDAGOGIA } \\
\text { HOSPITALAR: a } \\
\text { importância do pedagogo } \\
\text { como auxiliador do } \\
\text { aprendizado de crianças e } \\
\text { adolescentes } \\
\text { hospitalizados. }\end{array}$ & $\begin{array}{l}\text { Verificar a importância do papel } \\
\text { do pedagogo no ambiente } \\
\text { hospitalar, sendo norteados pelos } \\
\text { objetivos específicos: relatar } \\
\text { quais requisitos são necessários } \\
\text { para sua atuação, compreender as } \\
\text { competências e as habilidades do } \\
\text { pedagogo para o desenvolvimento } \\
\text { pedagógico com crianças e } \\
\text { adolescentes e bem como levantar } \\
\text { os desafios do pedagogo nas } \\
\text { práticas hospitalares }\end{array}$ & \\
\hline 2014 & Brasil & $\begin{array}{l}\text { A importância do } \\
\text { pedagogo no contexto } \\
\text { hospitalar }\end{array}$ & $\begin{array}{l}\text { Verificar as contribuições da } \\
\text { atuação do pedagogo para a } \\
\text { educação de crianças e } \\
\text { adolescentes } \\
\begin{array}{l}\text { no } \\
\text { hospitalar. }\end{array}\end{array}$ & \\
\hline 2019 & $\begin{array}{ll}\text { Brasil// Campo } & \text { Grande/MS }\end{array}$ & $\begin{array}{l}\text { Classe hospitalar: } \\
\text { práticas pedagógicas } \\
\text { desenvolvidas com } \\
\text { crianças dos anos iniciais } \\
\text { do ensino fundamental. }\end{array}$ & $\begin{array}{l}\text { Objetivo deste trabalho foi buscar } \\
\text { informações acerca do processo } \\
\text { de formação e das práticas } \\
\text { pedagógicas desenvolvidas por } \\
\text { profissionais da Educação que } \\
\text { atuam na classe hospitalar de um } \\
\text { hospital público em Campo } \\
\text { Grande/MS. }\end{array}$ & $\begin{array}{l}\text { Desde modo, torna-se importante } \\
\text { reconhecer o campo de atuação do } \\
\text { Pedagogo no contexto não escolar, } \\
\text { mostrando que a classe hospitalar é } \\
\text { organizada sob diversos aspectos, } \\
\text { integrando a escola, o contexto } \\
\text { familiar, a saúde, } \\
\text { criança/adolescente, etc. }\end{array}$ \\
\hline 2017 & Paraíba/Brasil & $\begin{array}{l}\text { A prática pedagógica no } \\
\text { ambiente hospitalar: um } \\
\text { estudo de caso no }\end{array}$ & $\begin{array}{l}\text { Objetivo analisar a prática } \\
\text { pedagógica dos educadores no } \\
\text { ambiente hospitalar, }\end{array}$ & $\begin{array}{l}\text { O pedagogo que opta por trabalhar } \\
\text { na área da Pedagogia Hospitalar } \\
\text { precisa estar apto a vivenciar novos }\end{array}$ \\
\hline
\end{tabular}


Research, Society and Development, v. 10, n. 15, e230101523209, 2021

(CC BY 4.0) | ISSN 2525-3409 | DOI: http://dx.doi.org/10.33448/rsd-v10i15.23209

\begin{tabular}{|c|c|c|c|c|}
\hline & & HULW. & $\begin{array}{l}\text { evidenciando sua relevância no } \\
\text { desenvolvimento dessa } \\
\text { atividade. }\end{array}$ & $\begin{array}{l}\text { desafios, especialmente em relação } \\
\text { à construção de novos saberes; pois } \\
\text { devem auxiliar no processo de } \\
\text { ensino-aprendizagem das crianças e } \\
\text { adolescentes com necessidades } \\
\text { especiais, pois a enfermidade no seu } \\
\text { período de internação se torna um } \\
\text { obstáculo à prática pedagógica. }\end{array}$ \\
\hline 2018 & $\begin{array}{l}\text { Mato Grosso do Sul/ } \\
\text { Brasil }\end{array}$ & $\begin{array}{l}\text { Práticas Pedagógicas no } \\
\text { espaço hospitalar: Um } \\
\text { projeto de extensão }\end{array}$ & $\begin{array}{l}\text { Objetivo a intenção de refletir as } \\
\text { práticas pedagógicas realizadas na } \\
\text { brinquedoteca da Clínica Escola da } \\
\text { Universidade Federal do Mato } \\
\text { Grosso do Sul que se dão no } \\
\text { cotidiano como uma possibilidade } \\
\text { e pretensão de vivenciar situações } \\
\text { práticas em um projeto de extensão } \\
\text { realizado no ano de } 2017 \text {. }\end{array}$ & $\begin{array}{l}\text { A brinquedoteca nesses espaços } \\
\text { com pedagogos (as) acabam por } \\
\text { proporcionar uma motivação nas } \\
\text { crianças, pois tem no brincar algo } \\
\text { prazeroso, fazendo com que os } \\
\text { tratamentos hospitalares sejam } \\
\text { afastados por algum momento ou } \\
\text { mesmo para revigorar forças e } \\
\text { continuar. }\end{array}$ \\
\hline 2013 & Brasil & $\begin{array}{lr}\text { Classe } & \text { Hospitalar: } \\
\text { Produção } & \text { do } \\
\text { Conhecimento em Saúde } \\
\text { e Educação. }\end{array}$ & $\begin{array}{l}\text { Objetivo foi analisar a produção } \\
\text { científica sobre classe hospitalar, a } \\
\text { fim de descrever a temática e os } \\
\text { aspectos abordados nos estudos } \\
\text { publicados. }\end{array}$ & $\begin{array}{l}\text { Esta abordagem apresenta estudos } \\
\text { que tratam das ligações, benefícios } \\
\text { e interferências que a classe } \\
\text { hospitalar traz para o processo de } \\
\text { hospitalização da criança e do } \\
\text { adolescente. O adoecimento, a } \\
\text { hospitalização e o impacto } \\
\text { emocional, provocados pela } \\
\text { terapêutica, alteram a rotina da } \\
\text { criança e sua família e podem } \\
\text { levar a criança e o adolescente à } \\
\text { desistência do papel de construtor } \\
\text { de sua história. }\end{array}$ \\
\hline 2018 & Brasil & $\begin{array}{l}\text { A prática pedagógica no } \\
\text { ambiente hospitalar. }\end{array}$ & $\begin{array}{l}\text { Busca-se identificar o atendimento } \\
\text { pedagógico-educacional no } \\
\text { ambiente hospitalar, suas praticas } \\
\text { educativas e escuta pedagógica. }\end{array}$ & $\begin{array}{l}\text { Os pedagogos rompem barreiras } \\
\text { das salas de aula tradicionais e } \\
\text { ocupam espaços alternativos de } \\
\text { escolarização, nesse caso os } \\
\text { hospitais, para esses profissionais. } \\
\text { Uma das dificuldades é que os } \\
\text { cursos de formação de } \\
\text { profissionais da saúde não } \\
\text { consideram o professor como } \\
\text { participante da equipe hospitalar. }\end{array}$ \\
\hline 2012 & Brasil & $\begin{array}{l}\text { A atuação do pedagogo } \\
\text { em classes hospitalares. }\end{array}$ & $\begin{array}{l}\text { Esse artigo teve por objetivo } \\
\text { investigar, através da pesquisa } \\
\text { bibliográfica, as práticas dos } \\
\text { pedagogos em classes hospitalares } \\
\text { buscando verificar as naturezas e } \\
\text { os tipos de mediações pedagógicas }\end{array}$ & $\begin{array}{l}\text { O pedagogo passa a ser um } \\
\text { vínculo fundamental existente } \\
\text { entre a realidade da hospitalização } \\
\text { e o contato com o que teve que ser } \\
\text { deixado para trás - a escola. }\end{array}$ \\
\hline
\end{tabular}




\begin{tabular}{|l|l|l|l|l|}
\hline & & $\begin{array}{l}\text { realizadas por esse profissional } \\
\text { para favorecer o aprendizado da } \\
\text { criança em classes hospitalares. }\end{array}$ & \\
\hline
\end{tabular}

Fonte: Pesquisa dos autores (2021).

No Quadro 1 é descrito os objetivos e características de cada estudo exposto, sintetizados pelo ano que foi publicado, qual cidade ou pais, titulo de cada artigo, objetivos gerais de cada um, e a revisão de literatura.

\section{Revisão de Literatura}

A pedagogia hospitalar é uma área da educação que por sua vez buscar da continuidade a escolarização para as crianças e adolescentes que se encontram hospitalizada. Desse modo, a educação no âmbito hospitalar tem um trabalho bem ampliado e diariamente faz analises com os alunos/pacientes como a situação física e emocional para poder criar um trabalho que venha ser adaptado e adequado a cada criança e adolescente que ali se encontra A construção da prática pedagógica em ambiente hospitalar implica preparo pedagógico, quando se trata de crianças e adolescentes hospitalizados, a pedagogia hospitalar não se restringir em apenas ser mais uma sala de aula dentro do hospital, mas sim um ambiente especializado pedagogicamente para os alunos/pacientes. Sendo assim, a prática pedagógica desenvolvida nesse ambiente tem adequações curriculares para poder atender as necessidades de cada aluno/paciente.

Segundo Gomes (2012, p. 2), destaca que a '"[...] Pedagogia Hospitalar busca novos conhecimentos, para beneficiar enfermos, principalmente jovens e crianças que se encontram hospitalizados, gerando quebras de paradigmas e lutando por qualidade de vida". Dentro dessas adequações pode se encontra a brinquedoteca, a brinquedoteca que:

É um espaço onde a criança e o adolescente se sente livre, usufruindo das oportunidades que possibilita desenvolverem novas competências, podendo ampliar seu desenvolvimento cognitivo, psíquico físico, social, psicomotor e emocional e assim poder aprender com o mundo, sobre as pessoas e principalmente sobre si mesmo, dessa forma a brinquedoteca buscar melhora uma qualidade melhor enquanto estiverem ali conforme o regimento "desenvolver um programa de ações lúdicas, culturais e socioeducativas, com a finalidade de amenizar o sofrimento causado pela hospitalização, elevando o grau de qualidade de vida da criança e seus familiares” (Regimento Interno Brinquedoteca, 2013, p. 2).

Nesse sentido a brinquedoteca é um espaço de entretenimento, lazer e interação, esse ambiente é de sumo importância dentro dos hospitais, pois é através dessas interações lúdicas que o pedagogo hospitalar percebe o desenvolvimento dessas crianças hospitalizadas. Esse regimento reconhece que a criança quando estando hospitalizada passa por período de dúvidas causado pelo distanciamento das atividades sociais diárias, como ir a escola, entre outras atividades a qual a criança esta inserida.

\section{Apresentar a importância da pedagogia nos hospitais}

A pedagogia hospitalar não é apenas repasso de conteúdo entre professor e aluno, vai muito além do que isso, é um suporte porque não vai isolar o aluno doente da escola, mas sim o manterá por dentro de todas as atividades escolares e também da família. Com as mudanças no mundo contemporâneo a pedagogia foi levada para outros espaços além da sala de aula. Esse novo papel do pedagogo que é esta dentro dos hospitais visa ofertar e dar seguimento aos estudos dos alunos que estão passando por problemas de saúde.

Nesse aspecto o pedagogo hospitalar ira lidar com uma educação mais diversificada, buscando trabalhar com atividades com mais criatividade conforme citado por Cardoso (2011, p. 57), “A ludicidade, com sua característica encantadora e benéfica para o desenvolvimento infantil, além de contribuir para o ensino-aprendizagem, cria um ambiente aconchegante e alegre no hospital". 
Como de conhecimento o hospital é um ambiente de tratamento, angústias, dor, sofrimento dentro outros itens e por esse motivo a pedagogia hospitalar entra nesse contexto para tratar da criança e adolescente que ali estar por um longo ou curto prazo, desde modo tem por finalidade introduzir ações didática e pedagógicas para proporcionar a criança e/ou jovem uma melhor vivência durante esse processo de tratamento que ocorre de forma bastante dolorosa, não apenas física, mas também e principalmente, psicológica e social, ajudando assim a criança a acolher e a compreender esse momento, bem como a vivê-lo de forma mais leve e também a resinificar a sua existência, o seu momento segundo Gomes (2012, p. 2) "a educação é o mais importante foco de uma sociedade, é com ela que nós desenvolvemos crescemos melhores como nação e como cidadãos".

\section{Identificar atuação e o desafio do pedagogo no âmbito da pedagogia hospitalar}

Como a Pedagogia trata da educação e um campo educativo muito vasto, a educação decorre diferentes modalidades, há também uma variedade de pedagogias e não apenas a pedagogia escolar, dentro dessa diversidade se encaixa a pedagogia hospitalar, uma área da educação que vem cuidar dos alunos permanece hospitalizados, onde o pedagogo tem sua participação no desenvolvimento da criança e adolescente, o trabalho do pedagogo no meio desse âmbito hospitalar, tanto na sala de apoio, classe ou no leito tem sua importância, o pedagogo se torna participante da equipe de profissional do hospital.

A atuação do pedagogo dentro do âmbito hospitalar ocorre através da prática pedagógica, sempre deve estar em buscas de novos conhecimentos, as atividades pedagógicas que o pedagogo juntamente com o hospital irá desenvolver para os alunos/pacientes serão de forma lúdicas, recreativas, proporcionar para as crianças e adolescentes que são atendidos uma boa recuperação tranquila principalmente porque o "hospital traz inquietações que envolvem sentimentos de dor, sofrimento e medo" (Rolim, 2019, p. 7).

A pedagogia hospitalar cria um elo entre esses alunos/pacientes hospitalizados fazendo com que previne eles do fracasso escolar gerado pelo afastamento da escola e fazendo uma ligação com o mundo que ficou lá fora. A pedagogia hospitalar é uma atividade transitória, que pode ocorrer em ambiente hospitalar ou domiciliar, de forma que a saúde da criança possa apresentar um quadro de evolução, além da continuidade do desenvolvimento social (Lima \& Silva Júnior, 2020).

Os maiores desafios que o pedagogo encontra é o conviver, aprender, colaborar com diferentes profissionais no hospital como o médico, psicóloga, pais, enfermeiro dentre outros profissionais, o pedagogo tem que ser sensível para poder ouvir diferentes opiniões para poder atingir seus objetivos e as metas especificas, porém, o maior desafio do pedagogo é o aprender a ser, pois isto exige dele pedagogo não só o conhecimento de si, mas de todos os que cercam. Mediante isto, o ambiente hospitalar também é um âmbito da educação e a participação do pedagogo é fundamental, pois do mesmo modo que a criança e adolescente necessita de atendimento médicos, também precisa da educação e o pedagogo faz-se necessário, pois ajudar as crianças um conhecer realidade nova, ajudar no processo de reabilitação e promover aulas que provoque alivio em vez de dores. "Alunos inseridos no contexto pedagógico de ambientes hospitalares, respondem de forma mais significativa em sua recuperação física" (Belancieri et al., 2018, p. 55).

\section{Desenvolvimento das práticas pedagógicas no âmbito hospitalar}

A legislação assegura que saúde e educação é para todos mediante a Constituição Federal de 1988, com isso o atendimento nas classes hospitalares perante a Lei Federal n $\mathrm{n}^{\circ}$ 9.394, de 20 de dezembro de 1996, ou seja, a Lei de Diretrizes e Bases da Educação Nacional - LDBEN ou LDB, no artigo 58, parágrafo $2^{\circ}$, consta que: "O atendimento educacional será feito em classes, escolas ou serviços especializados, sempre que, em função das condições específicas dos alunos, não for possível a sua integração nas classes comuns de ensino regular", porém as classes hospitalares ainda é pouco conhecida pelos estudantes de pedagogia conforme Saldanha e Simões (2013, p. 447): “[...] no Brasil, o início dessa ação educacional em ambiente não convencional é ainda pouco explorada e apresenta muitas lacunas" ou seja quando se fala em classe hospitalar logo se associa a 
área da saúde e não a uma área educacional devido os profissionais da educação pouco conhecer esse novo campo de atuação que abrange um espaço dentro da educação.

Desde modo, toda criança/adolescente tem direito de dar continuidade aos seus estudos "a pedagogia hospitalar mostra, portanto, que é um processo de educação organizada que transcende aos parâmetros usualmente adotados" (Matos \& Mugiatti, 2012 p.77). A prática pedagógica desenvolvida dentro das classes hospitalares faz com que esses alunos/pacientes possam continuar com seus estudos e o pedagogo deve garantir que isso aconteça, conhecer os conhecimentos adquiridos pelo aluno, conversar com seus responsáveis e a equipe multidisciplinar este é o primeiro para poder desenvolver as ações pedagógicas "[...] as práticas pedagógicas, se realizam para organizar/ potencializar/ interpretar as intencionalidades de um projeto educativo, de uma Pedagogia como sendo: crítico-emancipatória, como prática social, com pensamento reflexivo sobre o ocorre e o que pode ser a prática educativa" (Franco, 2016, p.537-538). Essas práticas educativas exigem que os pedagogos tenham bastante flexibilidade e reflexão na hora da realização dessas práticas. Sobre essas práticas educativas Bragança; Ferreira; Pontelo (2015):

[...] o professor tem um papel fundamental, ainda que ela não esteja centrada em suas ações, apenas dando pequenas orientações e fazendo observações. Mas deve-se lembrar de que ele, teve uma participação, a maior parte das vezes solitária, durante todo o organizar da prática, nesse processo, pode-se reconhecer a possibilidade da transgressão a partir das intenções do docente na mediação das interações entre o "mundo físico e o social". (Bragança et al. 2015, p. 2).

A prática educativa tem o intuído de levar para os alunos hospitalizados, uma compreensão de forma lúdica, conhecimento e conteúdos importantes e compreender que as práticas pedagógicas não se restringem apenas livros de didáticos. As práticas pedagógicas dentro dos hospitais evidenciam que o trabalho do pedagogo é suma importância para realização das atividades que é realizada com as crianças/adolescentes que ali se encontra, pois mesmo hospitalizadas e independentemente de sua classe social, raça ou origem ela criança/adolescente precisa de conhecimento, movimento, estudo e brincadeira. Toda criança é capaz de libera suas raivas e inseguranças, revive certas situações, contribuir com outras crianças e construir significados e desse modo qualquer cuidado concedido faz com que crianças/adolescentes percebam que estão vivos ativos e que são capazes.

\section{Considerações Finais}

Como se vê, o hospital é um espaço que abrange à educação e valorização do pedagogo em ambientes não escolares. Desse modo, a pedagogia hospitalar é um local aonde vem sendo conquistado aos poucos pelos pedagogos, a atuação do pedagogo nos hospitais é importante, pois o pedagogo possui o papel social transmissor de conhecimento, uns asseguram, uma esperança para os acompanhantes e alunos-pacientes, proporcionando o desenvolvimento e a aprendizagem, auxiliando no processo de reabilitação e conquistando em todo o tempo, o bem estar da criança, fazer com que as perdas no processo de internação seja os menores possíveis.

A função do pedagogo no processo de ensino aprendizagem das crianças/adolescentes hospitalizadas faz com que elas sentem mais ânimo, para resgatar os sentimentos de autoestima, aceitação, segurança, e estimulo para passar pelo processo de tratamento, atingir uma boa recuperação e continuar com seus estudos. O pedagogo é de fato um valor estimável dentro de o ambiente hospitalar, pois é de fato que esses educadores devem ser reconhecidos como profissionais da educação que são, e não apenas como recriadores. 
Deste modo o que é feito com ética, capacitação, profissionalismo, sensibilidade e amor faz-se possível um bom trabalho, agindo dessa forma poderemos ter alegria nos corredores frios dos hospitais e crianças podendo ter sua infância mesmo não sendo em condições favorável em relação a saúde e ao seu bem-estar.

Acreditamos que este trabalho sirva como fonte de documentos para que o leitor possa desfrutar e apreciar sobre a atuação do pedagogo com alunos e pacientes em ambiente hospitalar. Consentindo refletir que este profissional, possa agir em vários segmentos, não somente em ambiente escolar.

Por fim, para trabalhos futuros sugere-se que seja feito uma pesquisa de campo abordando a importância do pedagogo nos âmbitos hospitalares e como se dá a formação, e como esses profissionais executaram seu trabalho durante a pandemia da corona vírus (covid-19).

\section{Referências}

Brasil, E. (2016) Pedagogia Hospitalar: Metas E Desafios Para O Pedagogo: Análise dos principais desafios enfrentados pelos pedagogos que atuam em hospitais e as metas que almejam alcançar. https://www.google.com/amp/s/m.meuartigo.brasilescola.uol.com.br/amp/pedagogia/pedagogia-hospitalar-metasdesafios-para-pedagogo.htm

Matos, E. L. M., \& de Freitas Mugiatti, M. M. T. (2017). Pedagogia Hospitalar: a humanização integrando educação e saúde. Editora Vozes Limitada.

Camargos, E. S., de Castro Camargos, M. D., de Mello, R. S. V., \& de Almeida, G. H. (2020). O direito à educação da criança hospitalizada. LIBERTAS: Revista de Ciênciais Sociais Aplicadas, 10(2), 165-194.

Gil, A. C. (2002). Como classificar as pesquisas. Como elaborar projetos de pesquisa, 4, 44-45. Editora Academia

Pontes, M. D. S. (2018). A importância da pedagogia no ambiente hospitalar. Editora Repositório UFPB

Cardoso, M. R. (2011). Desafios e possibilidades da ludicidade no atendimento pedagógico hospitalar.

Souza, Z. S., \& Rolim, C. L. A. (2019). As vozes das Professoras na Pedagogia hospitalar: descortinando Possibilidades e enfrentamentos. Revista Brasileira de Educação Especial, 25, 403-420.

Pessoa, A. C. B., Souza, M., \& Fontes, F. (2012). O lúdico no ambiente hospitalar: algumas reflexões. Campina Grande: Editora Realize

Lima1 ${ }^{1}$ A. J. A., \& Júnior, R. S. (2020). O pedagogo hospitalar: atuação e contribuições. Editora realize.

Amorim, V. M. (2015). A dimensão pedagógica do pedagogo hospitalar. Editora Biblioteca Digital de Monografia-BDM

de Souza, L. M., dos Reis Dias, G. K., da Silva, F. L., \& Perpétuo, C. L. (2018). Pedagogia hospitalar: conceito e importância frente aos direitos da criança hospitalizada. Educere-Revista da Educação da UNIPAR, 18(1).

Russo, J. G., \& Messa, S. P. (2017). Pedagogia Hospitalar: a importância do pedagogo como auxiliador do aprendizado de crianças e adolescentes hospitalizados. Revista Saberes Docentes, 2(4).

Ferreira, S. G. B. D. S., \& Cardoso, J. M. (2014). A importância do pedagogo no contexto hospitalar. Editora Fama Portal

Gouveia, B. M. C. (2018) O papel do pedagogo na classe hospitalar. Editora realize

Custódio, T. P., \& Silva, M. B. (2019). Classe hospitalar: práticas pedagógicas desenvolvidas com crianças dos anos iniciais do ensino fundamental. Formação Docente-Revista Brasileira de Pesquisa sobre Formação de Professores, 11(20), 163-180.

Souza, A. C. S. D. (2017). A prática pedagógica no ambiente hospitalar: um estudo de caso no HULW. Editora Repositório UFPB

Santa Cruz, A., de Oliveira, A. R. L., \& Silva, M. B. (2018). Práticas Pedagógicas No Espaço Hospitalar: Um Projeto De Extensão. Jornada Brasileira De Educação E Linguagem/Encontro Do Profeduc E Profletras/Jornada De Educação De Mato Grosso Do Sul, 1(1).

Xavier, T. G. M., Araújo, Y. B. D., Reichert, A. P. D. S., \& Collet, N. (2013). Classe hospitalar: Produção do conhecimento em saúde e educação. Revista Brasileira de Educação Especial, 19, 611-622.

Ruivo, G. F. C. A prática pedagógica no ambiente hospitalar. Editora Multivix.

Tinée ${ }^{1}$, C. A., \& Ataide, S. P. (2012). A atuação do pedagogo em classes hospitalares. Editora Paradigma. 